\title{
Bibliometric Analysis of Srels Journal of Information Management (2000-2013)
}

\author{
Smt. Madhuri Gautam, Dr. Maya Verma \\ ${ }^{1}$ Assistant Librarian Pt. K.L.S. College of Horticulture Rajnandgaon (Chhattisgarh) \\ ${ }^{2}$ Professor (Lib.\& Inf.Sci.) Pt. R.S. University, Raipur (Chhattisgarh)
}

\begin{abstract}
The bibliometrics analysis of the journal "SRELS journal of information management (2000-2013)" shows a trend of growth in contribution and average number of contribution is 44.78 per volume. Majority of the library and information scientists prefer to do collaborative research and contribute their papers jointly. Majority of the library and information scientists have cited journals in large number 2900 (40.57\%) while books comes on second with 2090 (29.24\%) citations.
\end{abstract}

Keywords: Bibliometric, citation analysis Authorship trend, library and information science, collaborative research

\section{Introduction}

The term bibliometrics was first used by Alan Pritchard in 1969 and defined it as study of the "Application of Mathematics and Statistical methods to books and other media of communication." Bibliometric is a quantitative evaluation of publication pattern of all micro and micro communication along with their authorship by mathematical and statistical calculation. Bibliometrics can be applied to any subject area and to most of the problems concerned with written communication.

\section{Objectives}

The main objectives of this study are:

1. To find out year-wise distribution of publication.

2. To find out the authorship pattern.

3. To find out the volume-wise degree of collaboration.

4. To obtain the form at dispersion of references in SRELS journal of information Management.

5. To find out average number of contributions per volume.

\section{Review of Literature}

1. Dixit and Katare (2007) studies the collaborative research trend in the field of cotton science. Observations are based on the ten year data (1996-2005). Collected from the journal of the Indian Society for Cotton Improvement (ISCI journal). Readings show that the number of multi-authored paper (91.04\%) surpassed the single authored papers $(8.95 \%)$. The degree of collaboration in the field of cotton science is 0.91 . The study reinforces the fact that scientific research is group oriented.

2. Rana and Agarwal (1994). Studied the paper on authorship trends in Indian Wildlife and Fisheries. State that the degree of collaborative research and the average number of anthers per paper have a steady rise.

3. Visakhi and Srivastava (2002). Studied the paper on research trends in the field of statistical science also endorse the same view. As per their observations. The percentage of multi anthors has raised from $18.34 \%$ in 1965 to $65.45 \%$ in 2000 .

4. Sentilkumaran and Vedivel (2003). Studied the journal "spice India' from 1997-2001. His finding shows that one anther contribution is 51.29 and three and more than three contributions are only $15 \%$. In case of length of articles, $1-3$ pages contribution was $82.84 \%$. This trend indicated that most of articles were popular statistical reports which were very helpful to planters/farmers in spice crop cultivation.

\section{Methodology}

A total of 62 issues of the journal SRELS journal of information Management a leading journal of library and information science (2000-2013) was selected. Its publication was started in 1964 with four issues in a year. This journal is published by Sarda Ranganathan Endowment for library science Bangalore. The study of Bibliometric in this journal was evaluated from vol. 37 to 50 (2000-2013). Each of vol. (i.e. 27 to 46) was published in 4 issues in a single year but vol. 46 (2010) had published in 6 issues in a year.

The details regarding each published article such as title of the article, number of authors, number at reference, number of tables and figures etc. were recorded and analyzed for waking observations. Tables are 
filed by tally mark system counting one by one reference and after data. The data has been calculated and represented in table.

\section{Data Analysis and interpretation}

1. Distribution of contribution

Table - 1 Volume wise Distribution of Contribution

\begin{tabular}{|c|l|c|c|c|c|}
\hline $\begin{array}{r}\text { SI. } \\
\text { No. }\end{array}$ & \multicolumn{1}{|c|}{ Year } & $\begin{array}{c}\text { Vol. } \\
\text { No. }\end{array}$ & $\begin{array}{c}\text { No. of } \\
\text { issues }\end{array}$ & $\begin{array}{c}\text { No. of } \\
\text { cont. }\end{array}$ & $\%$ \\
\hline 1 & March 2000- Dec.2000 & 37 & 04 & 22 & $3.50 \%$ \\
\hline 2 & March 2001- Dec.2001 & 38 & 04 & 36 & $5.74 \%$ \\
\hline 3 & March 2002- Dec.2002 & 39 & 04 & 39 & $6.22 \%$ \\
\hline 4 & March 2003- Dec.2003 & 40 & 04 & 35 & $5.58 \%$ \\
\hline 5 & March 2004- Dec.2004 & 41 & 04 & 38 & $6.06 \%$ \\
\hline 6 & March 2005- Dec.2005 & 42 & 04 & 37 & $5.90 \%$ \\
\hline 7 & March 2006- Dec.2006 & 43 & 04 & 34 & $5.42 \%$ \\
\hline 8 & March 2007- Dec.2007 & 44 & 04 & 36 & $5.74 \%$ \\
\hline 9 & March 2008- Dec.2008 & 45 & 04 & 49 & $7.81 \%$ \\
\hline 10 & March 2009- Dec.2009 & 46 & 04 & 44 & $7.01 \%$ \\
\hline 11 & March 2010- Dec.2010 & 47 & 04 & 62 & $9.88 \%$ \\
\hline 12 & March 2011- Dec.2011 & 48 & 06 & 62 & $9.88 \%$ \\
\hline 13 & March 2012- Dec.2012 & 49 & 06 & 64 & $10.20 \%$ \\
\hline 14 & March 2013- Dec.2013 & 50 & 06 & 69 & $11.00 \%$ \\
\hline \multicolumn{7}{|c|}{ 14 Year } & $\mathbf{1 4}$ Vol. & $\mathbf{6 2}$ & $\mathbf{6 2 7}$ & $\mathbf{1 0 0 \%}$ \\
\hline
\end{tabular}

Graph showing volume wise, contributions this graph shown that the numbers of contribution are increasing day by day in later volumes of the journal. Most significant part of this chart is that it is showing a continues growth in the publication of contributions volume by volume.

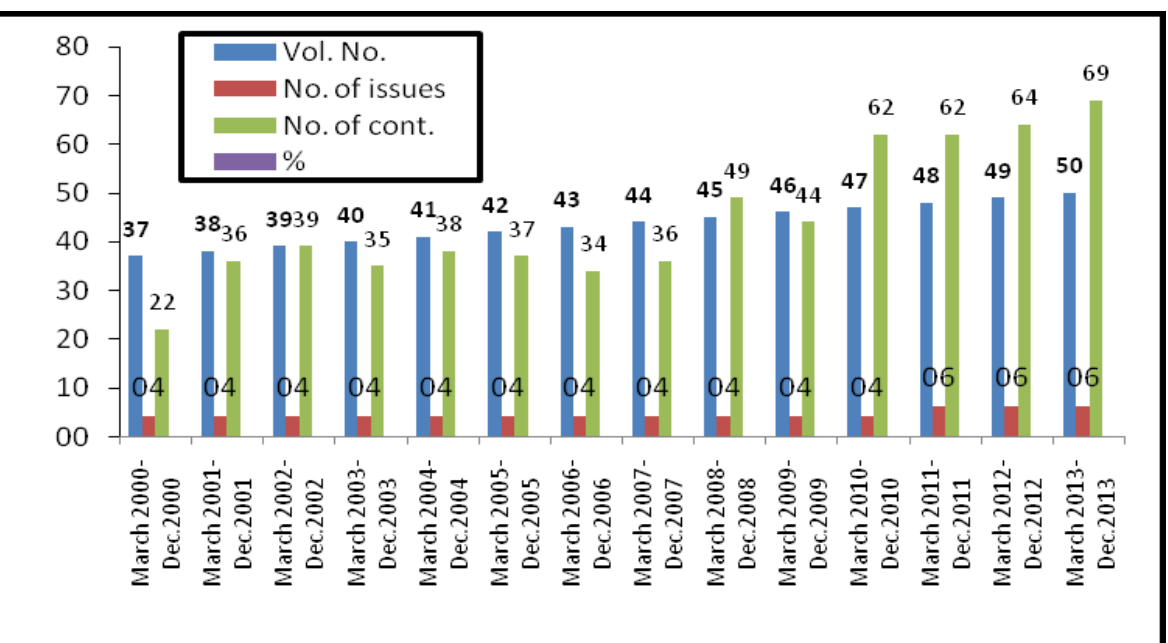

Table - 2 Authorship pattern of contribution

\begin{tabular}{|c|c|c|}
\hline No. of Authors & $\begin{array}{c}\text { No. of } \\
\text { contributions }\end{array}$ & $\%$ \\
\hline One & 234 & $37.32 \%$ \\
\hline Two & 312 & $49.76 \%$ \\
\hline Three & 64 & $10.20 \%$ \\
\hline More then Three & 17 & $2.71 \%$ \\
\hline Total & $\mathbf{6 2 7}$ & $\mathbf{1 0 0 \%}$ \\
\hline
\end{tabular}

Growing showing Authorship Pattern 


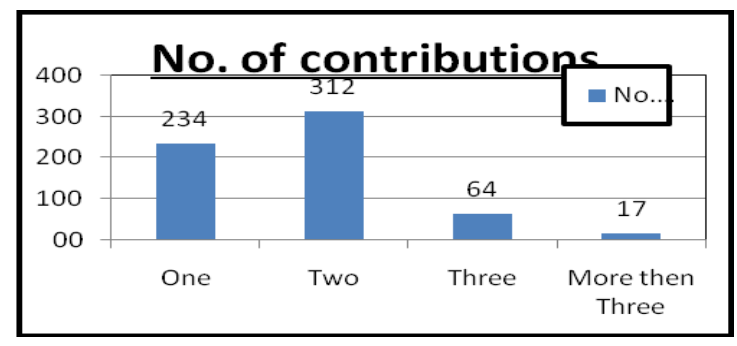

Table-2 shows that the contributions of double authors are more than those of single, triple or more Than triple authors. The multiple authorship pattern has the most productive publication i.e. 393 (63.30\%) papers while the single authorship pattern has 234 (37.32\%) papers. The multiple authorship patterns are further analyzed to shed more light on the pattern of collaboration. Publication with two authors are $312(49.76 \%)$ paper followed by three authorship pattern with $64(10.20 \%)$ paper and, more than three authorship pattern have 17 $(2.79 \%)$ papers.

Table-3 Authorship pattern at contributions (volume-wise)

\begin{tabular}{|c|c|c|c|c|c|c|c|c|}
\hline Volume & 1 Author & $\%$ & 2 Author & $\%$ & 3 Author & $\%$ & $\begin{array}{c}\text { more } \\
\text { then } 3 \\
\text { Author }\end{array}$ & $\%$ \\
\hline 37 & 11 & $4.70 \%$ & 09 & $3.84 \%$ & 02 & $3.12 \%$ & - & - \\
\hline 38 & 16 & $6.83 \%$ & 20 & $6.41 \%$ & - & - & - & - \\
\hline 39 & 23 & $9.82 \%$ & 09 & $3.84 \%$ & 05 & $7.81 \%$ & 02 & $11.76 \%$ \\
\hline 40 & 13 & $5.55 \%$ & 16 & $5.12 \%$ & 05 & $7.81 \%$ & 01 & $5.88 \%$ \\
\hline 41 & 17 & $7.26 \%$ & 19 & $6.08 \%$ & 01 & $1.56 \%$ & 02 & $11.76 \%$ \\
\hline 42 & 12 & $5.12 \%$ & 22 & $7.05 \%$ & 03 & $4.68 \%$ & - & - \\
\hline 43 & 10 & $4.27 \%$ & 17 & $5.44 \%$ & 05 & $7.81 \%$ & 02 & $11.76 \%$ \\
\hline 44 & 18 & $7.65 \%$ & 14 & $4.48 \%$ & 02 & $3.12 \%$ & 01 & $5.88 \%$ \\
\hline 45 & 16 & $6.83 \%$ & 28 & $8.97 \%$ & 04 & $6.25 \%$ & 01 & $5.88 \%$ \\
\hline 46 & 17 & $7.26 \%$ & 24 & $7.69 \%$ & 03 & $4.68 \%$ & - & - \\
\hline 47 & 18 & $7.69 \%$ & 31 & $9.93 \%$ & 10 & $15.62 \%$ & 03 & $17.64 \%$ \\
\hline 48 & 18 & $7.69 \%$ & 36 & $11.53 \%$ & 05 & $7.81 \%$ & 03 & $17.64 \%$ \\
\hline 49 & 23 & $9.82 \%$ & 32 & $10.25 \%$ & 07 & $10.93 \%$ & 02 & $11.76 \%$ \\
\hline 50 & 22 & $9.40 \%$ & 35 & $11.21 \%$ & 12 & $18.75 \%$ & - & \\
\hline TOTAL & 234 & $100 \%$ & 312 & $100 \%$ & 64 & $100 \%$ & 17 & $100 \%$ \\
\hline
\end{tabular}

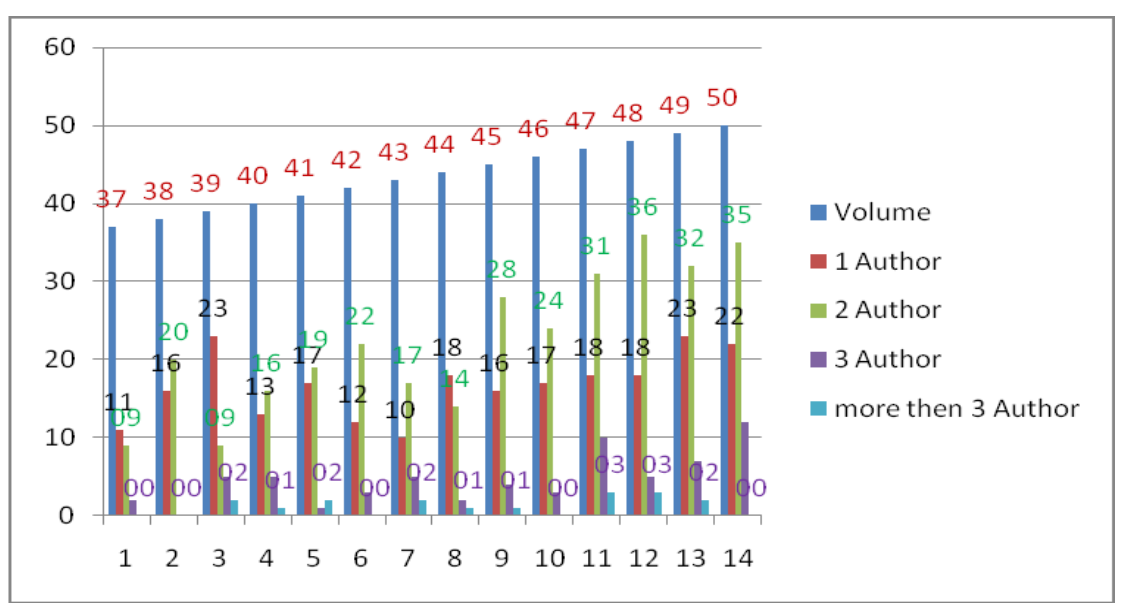

The above table shows the trends in authorship pattern, as multi authored papers are leading in frequency of occurrence in the journal "SRELS Journal information Management." Throughout the study and more interestingly this growth is continuous which indication about the future pattern in authorship.

The highest numbers of contributions in the category of single authorship are contributed in 2002 and 2012 which are $23(9.82 \%)$ out of 234 single authored paper while in the category of multi authored papers the highest number of contributions are contributes in the year 2006 having $36(11.53 \%)$ contributions out of 312 contributions. 
Table - 04 Single authored V/s Multi Authored paper.

\begin{tabular}{|c|c|c|c|c|c|}
\hline \multirow[b]{2}{*}{ Year } & \multicolumn{2}{|c|}{ With Single Author } & \multicolumn{2}{|c|}{ With Multi Author } & \multirow{2}{*}{$\begin{array}{c}\text { Total } \\
\text { contribution }\end{array}$} \\
\hline & $\begin{array}{l}\text { No. of } \\
\text { Papers }\end{array}$ & $\%$ & $\begin{array}{l}\text { No. of } \\
\text { paper }\end{array}$ & $\%$ & \\
\hline 2000 & 11 & $4.70 \%$ & 11 & $3.52 \%$ & 22 \\
\hline 2001 & 16 & $6.83 \%$ & 20 & $6.41 \%$ & 36 \\
\hline 2002 & 23 & $9.82 \%$ & 16 & $5.12 \%$ & 39 \\
\hline 2003 & 13 & $5.55 \%$ & 22 & $7.05 \%$ & 35 \\
\hline 2004 & 17 & $7.26 \%$ & 22 & $7.05 \%$ & 39 \\
\hline 2005 & 12 & $5.12 \%$ & 25 & $8.01 \%$ & 37 \\
\hline 2006 & 10 & $4.27 \%$ & 24 & $7.69 \%$ & 34 \\
\hline 2007 & 18 & $7.65 \%$ & 18 & $5.44 \%$ & 36 \\
\hline 2008 & 16 & $6.83 \%$ & 33 & $10.57 \%$ & 49 \\
\hline 2009 & 17 & $7.26 \%$ & 27 & $8.65 \%$ & 44 \\
\hline 2010 & 18 & $7.69 \%$ & 44 & $14.10 \%$ & 62 \\
\hline 2011 & 18 & $7.69 \%$ & 44 & $14.10 \%$ & 62 \\
\hline 2012 & 23 & $9.82 \%$ & 41 & $13.14 \%$ & 64 \\
\hline 2013 & 22 & $9.40 \%$ & 47 & $15.06 \%$ & 69 \\
\hline TOTAL & 234 & $100 \%$ & 393 & $100 \%$ & 627 \\
\hline
\end{tabular}

Graph showing single \& Multi Authorship

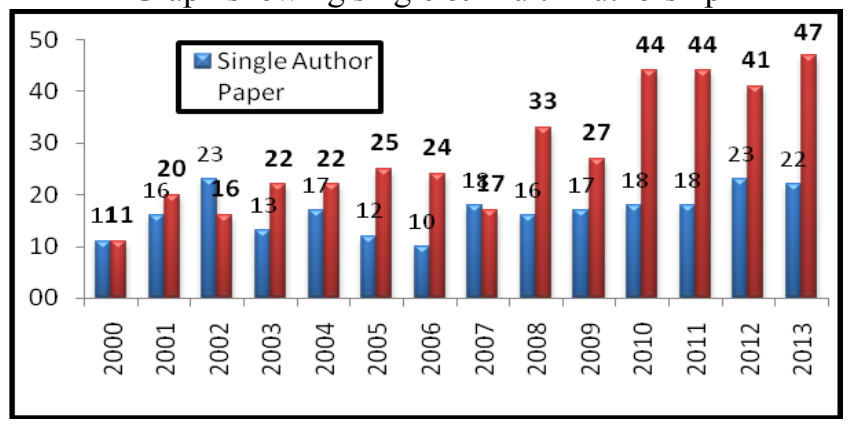

The above graph shows that in every volume of the journal "SRELS journal of information management", the number of multi authored papers are dominating to single authored papers. The overall multi authored paper are more than two time, of single authors papers. It reveals that now the library and information science field is heavily influence by the collaborative research.

\section{Degree of Collaboration :}

The degree of collaboration among authors is measured by The following for mula given by K. Subramanyam:

Where,

$$
\mathrm{C}=\frac{\mathrm{Nm}}{\mathrm{Nm}+\mathrm{Ns}}
$$

$$
\begin{array}{lll}
\mathrm{C} & = & \text { Degree of collaboration } \\
\mathrm{Nm} & = & \text { Number of multi authors contribution } \\
\mathrm{Ns} & = & \text { Number of single Authored contributions. }
\end{array}
$$

In the present study the value of $\mathrm{C}$ is

$$
C=\frac{393}{393+234}=\frac{393}{627}=0.62 \%
$$

Thus the degree of collaboration in the journal "SRELS journal of information management is 0.62 , this brings out clearly the prevalence of team research in library and information science field. The distribution of degree of collaboration over the year from 2000 to 2013 is presented in table- 5 . 
Table - $\mathbf{5}$ yearwise distribution of Degree of Collaboration

\begin{tabular}{|c|c|c|c|}
\hline Year & $\begin{array}{c}\text { single } \\
\text { authors }\end{array}$ & $\begin{array}{c}\text { multi } \\
\text { authors }\end{array}$ & $\begin{array}{c}\text { degree of } \\
\text { collaboration }\end{array}$ \\
\hline 2000 & 11 & 11 & 0.50 \\
\hline 2001 & 16 & 20 & 0.55 \\
\hline 2002 & 23 & 16 & 0.41 \\
\hline 2003 & 13 & 22 & 0.62 \\
\hline 2004 & 17 & 22 & 0.59 \\
\hline 2005 & 12 & 25 & 0.67 \\
\hline 2006 & 10 & 24 & 0.50 \\
\hline 2007 & 18 & 18 & 0.67 \\
\hline 2008 & 16 & 33 & 0.50 \\
\hline 2009 & 17 & 27 & 0.67 \\
\hline 2010 & 18 & 44 & 0.61 \\
\hline 2011 & 18 & 44 & 0.70 \\
\hline 2012 & 23 & 41 & 0.64 \\
\hline 2013 & 22 & 47 & 0.68 \\
\hline TOTAL & $\mathbf{2 3 4}$ & $\mathbf{3 9 4}$ & $\mathbf{0 8}$ \\
\hline
\end{tabular}

It is very interesting to record that the degree of collaboration in the journal "SRELS journal of information Management." over the period of study varied from 0.50 to 0.70 .

Graph Showing Degree of Collaboration

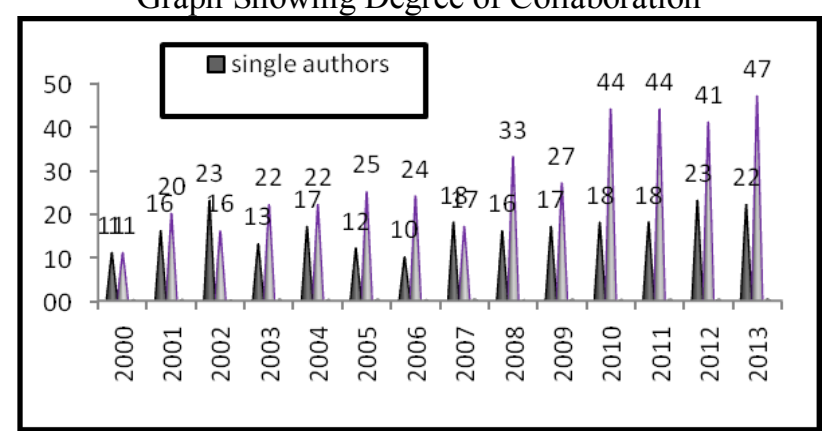

This graph shows the distribution of degree of collaboration over 2000 to 2013 in the journal "SRELS journal of information is highest in the year 2010 \& 2011 while it is lowest in the year 2000 and 2006.

\section{Citation Studies:}

Distribution at citations (Volume-wise)

\begin{tabular}{|c|c|c|}
\hline $\begin{array}{c}\text { Volume } \\
\text { No. }\end{array}$ & $\begin{array}{c}\text { No of } \\
\text { Citations }\end{array}$ & $\%$ \\
\hline 37 & 200 & $2.79 \%$ \\
\hline 38 & 213 & $2.98 \%$ \\
\hline 39 & 435 & $6.08 \%$ \\
\hline 40 & 394 & $5.51 \%$ \\
\hline 41 & 374 & $5.23 \%$ \\
\hline 42 & 323 & $4.51 \%$ \\
\hline 43 & 387 & $5.41 \%$ \\
\hline 44 & 461 & $6.45 \%$ \\
\hline 45 & 528 & $7.38 \%$ \\
\hline 46 & 502 & $7.02 \%$ \\
\hline 47 & 558 & $7.80 \%$ \\
\hline 48 & 813 & $11.37 \%$ \\
\hline 49 & 804 & $11.24 \%$ \\
\hline 50 & 1155 & $16.16 \%$ \\
\hline TOTAL & $\mathbf{7 1 4 7}$ & $100 \%$ \\
\hline
\end{tabular}




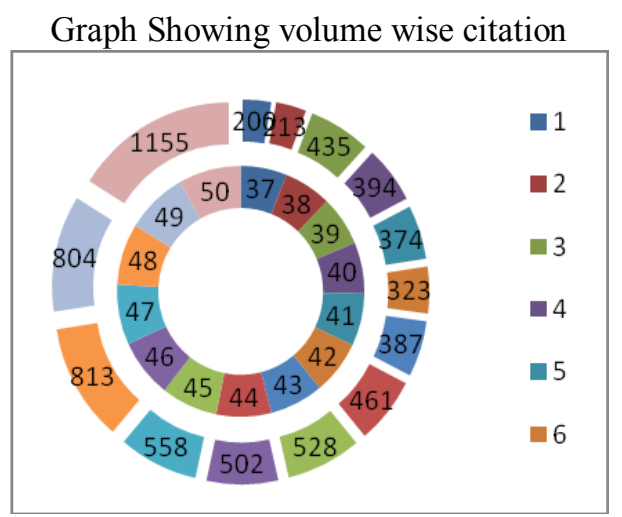

The above figure shows that volume 50 has highest number of share (16.16\%) in the total citation i.e., 7147 received during the study. While teast citation has been received in volume number 37 with $2.79 \%$ citations. Tatol 7147 citation have been recorded in 627 contributation therefore the average number of citation per contribution is 11.39 which is good enough.

Table - 7 Average Citations per Contribution in each Volume.

\begin{tabular}{|c|c|c|c|}
\hline $\begin{array}{c}\text { Volume } \\
\text { No. }\end{array}$ & $\begin{array}{c}\text { No. of } \\
\text { Contribution }\end{array}$ & $\begin{array}{c}\text { No. of } \\
\text { Citation }\end{array}$ & Average \\
\hline 37 & 22 & 200 & $9.09 \%$ \\
\hline 38 & 36 & 213 & $5.99 \%$ \\
\hline 39 & 39 & 435 & $11.15 \%$ \\
\hline 40 & 35 & 394 & $11.25 \%$ \\
\hline 41 & 38 & 374 & $9.84 \%$ \\
\hline 42 & 37 & 323 & $8.72 \%$ \\
\hline 43 & 34 & 387 & $11.38 \%$ \\
\hline 44 & 36 & 461 & $12.80 \%$ \\
\hline 45 & 49 & 528 & $10.77 \%$ \\
\hline 46 & 44 & 502 & $11.40 \%$ \\
\hline 47 & 62 & 558 & $9.00 \%$ \\
\hline 48 & 62 & 813 & $12.90 \%$ \\
\hline 49 & 64 & 804 & $12.56 \%$ \\
\hline 50 & 69 & 1155 & $16.73 \%$ \\
\hline TOTAL & $\mathbf{6 2 7}$ & $\mathbf{7 1 4 7}$ & $\mathbf{1 1 . 3 9 \%}$ \\
\hline
\end{tabular}

Graph showing Average Citations

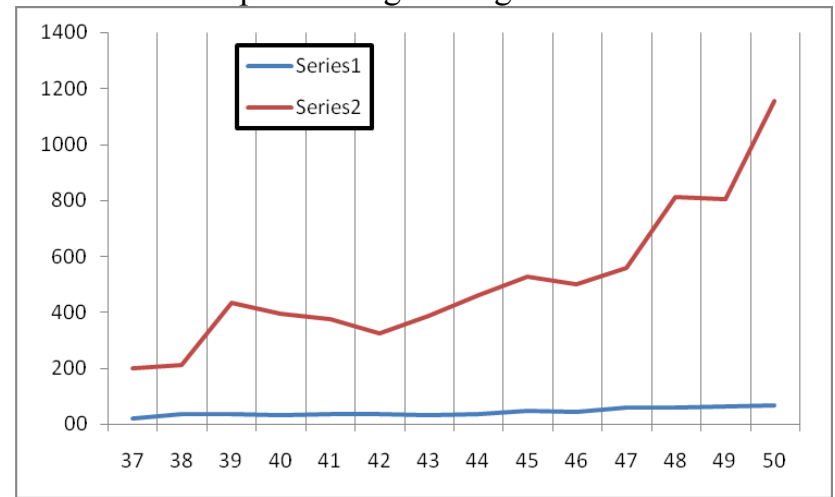




\section{Bibliographical distribution}

Table - 8, Types of publication cited

\begin{tabular}{|c|c|c|c|c|}
\hline Types of publication Cited & $\begin{array}{c}\text { No. of } \\
\text { Citation }\end{array}$ & $\%$ & Cumulative & $\%$ \\
\hline Journal & 2900 & $40.57 \%$ & 2900 & $40.57 \%$ \\
\hline Books & 2090 & $29.24 \%$ & 4990 & $70.51 \%$ \\
\hline Conference Proceedings & 392 & $5.48 \%$ & 5382 & $75.30 \%$ \\
\hline Theses & 116 & $1.62 \%$ & 5498 & $77.69 \%$ \\
\hline Reports & 214 & $2.99 \%$ & 5712 & $79.92 \%$ \\
\hline Www (world wide web) & 1435 & $20.07 \%$ & $\mathbf{7 1 4 7}$ & $100 \%$ \\
\hline TOTAL & $\mathbf{7 1 4 7}$ & $\mathbf{1 0 0 \%}$ & & \\
\hline
\end{tabular}

Table-8, Shows that journals occupy $40.57 \%$ citations which are in number 2900 out of total 7147 citations. Books have $2090(29.24 \%)$ citations. conference proceeding out of total 7147 citations. Theses have total $116(1.62 \%)$ citations in its account out of total 7147, Report have $214(2.99 \%)$ citations. World Wide Web have $1435(20.07 \%)$ citations in its account out of total 7147.

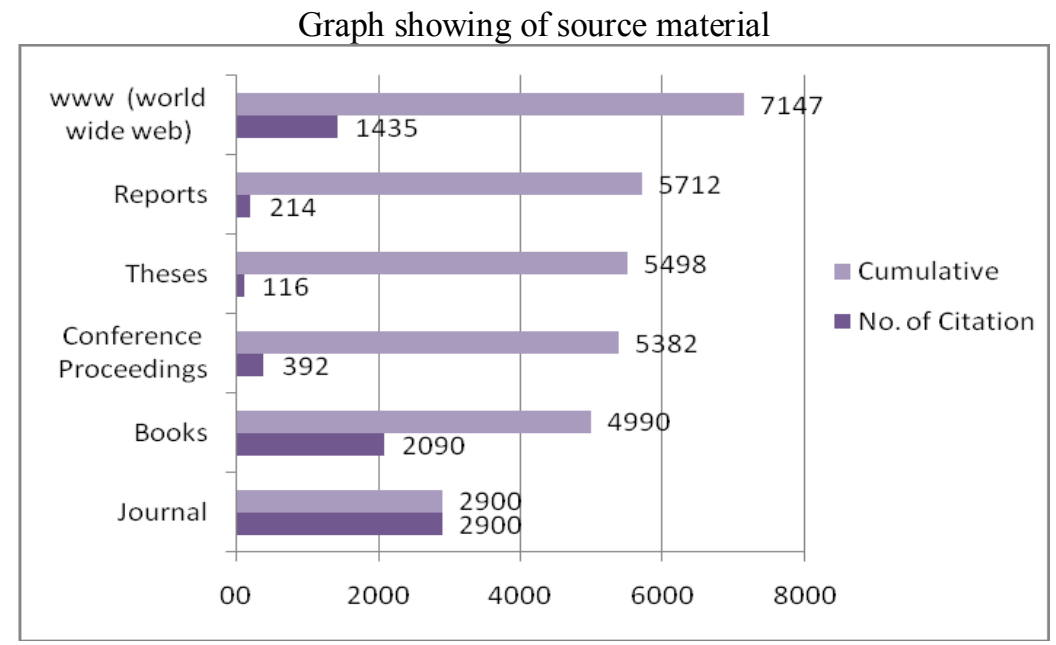

This graph shows that journal is leading in all the sources cited by the anthors during the research articles writing and other research Proparation. Books are second highest cited items followed by the conference proceeding having $392(5.48 \%)$ citation. Web resourcses (www) have 1435 (20.07\%) citations.

\section{Results and findings}

The following results and conclusions can be drawn from the bibliometric analysis of the journal "SRELS journal of information management (2000-2013)".

* This study shows a trend of growth in contributions published during 2000 to 2013 and average number of contribution per volume 44.78 .

* Majority of the library and information scientists prefer to contribute their papers jointly.

- Majority of the library and information scientists have cited journals in large number 2900 (40.57\%) while books comes on second with 2090 (29.24\%) citations.

- Most of the contribution are with citations. Only one contribution is found with citation out of total 627 contributions.

\section{References}

[1]. Ravichandra Rao, I.K. Quantitative Techniques for Library and Information Science, New Delhi. Wiley Eastern. P.12-15.

[2]. Sengupta, IN. (1990) Bibliometrics and identification of case periodicals. Herald of Library Science . P.226-234.

[3]. Mahapatra, Gayatri (2000), Bibliometric Studies on library and information science literature. Delhi.: Crust.

[4]. Dixit, Swati and V.V. Katare (2007). Investigations in collaborative research Trends among Indian Cotton Scientists (1996-2005) IASLIC Bulletin. 52.3 P.137-142.

[5]. Rana. M.S. and Sunita Agrawal (1994). Authorship trends in Indian wildlife and fisheries literature- a bibliometric study. Annals of Library Science and Documentation. 41.1: P.13-18.

[6]. Viskhi, P. and S.S. Srivastava. Current trend of research collaboration in the field of statistrical science - a case study. IASLIC bulletin. 47.4: P.210-215

[7]. SenthiKumaram, P. and vadivel (2003). Spice India a bibliometric study. SRELS journal of information Management. 40.4: 431438. 